ARTICLE

Received 14 Nov 2014 | Accepted 20 May 2015 | Published 9 Jul 2015

DOI: $10.1038 /$ ncomms 8592

OPEN

\title{
Rapid neodymium release to marine waters from lithogenic sediments in the Amazon estuary
}

Tristan C.C. Rousseau ${ }^{1}$, Jeroen E. Sonke ${ }^{1}$, Jérôme Chmeleff ${ }^{1}$, Pieter van Beek ${ }^{2}$, Marc Souhaut ${ }^{2}$, Geraldo Boaventura ${ }^{3}$, Patrick Seyler ${ }^{4} \&$ Catherine Jeandel ${ }^{2}$

Rare earth element (REE) concentrations and neodymium isotopic composition ( $(\mathrm{Nd})$ are tracers for ocean circulation and biogeochemistry. Although models suggest that REE release from lithogenic sediment in river discharge may dominate all other REE inputs to the oceans, the occurrence, mechanisms and magnitude of such a source are still debated. Here we present the first simultaneous observations of dissolved $(<0.45 \mu \mathrm{m})$, colloidal and particulate REE and $\varepsilon N d$ in the Amazon estuary. A sharp drop in dissolved REE in the low-salinity zone is driven by coagulation of colloidal matter. At mid-salinities, total dissolved REE levels slightly increase, while $\varepsilon N d$ values are shifted from the dissolved $\mathrm{Nd}$ river endmember $(-8.9)$ to values typical of river suspended matter ( -10.6$)$. Combining a Nd isotope mass balance with apparent radium isotope ages of estuarine waters suggests a rapid (3 weeks) and globally significant $\mathrm{Nd}$ release by dissolution of lithogenic suspended sediments.

\footnotetext{
${ }^{1}$ GET, Université de Toulouse, CNRS, IRD, CNES, 14 Avenue Edouard Belin, Toulouse F-31400, France. ${ }^{2}$ LEGOS, Université de Toulouse, CNRS, IRD, CNES, 14 Avenue Edouard Belin, Toulouse F-31400, France. ${ }^{3}$ Universidade De Brasilia, UNB, LAGEQ, Campus universitário Darcy Ribeiro, Brasilia, DF 70.910-900, Brazil. ${ }^{4}$ Hydrosciences Montpellier, Université de Montpellier-IRD-CNRS, Place Eugène Bataillon 34000, France. Correspondence and requests for materials should be addressed to T.C.C.R. (email: tristanrousseau@yahoo.fr) or to J.E.S. (email: jeroen.sonke@get.omp.eu) or to C.J. (email: Catherine.Jeandel@legos.obs-mip.fr).
} 
U nderstanding rare earth element (REE) speciation, dynamics and mass balance in natural waters is important because $\mathrm{REE}$ and neodymium $(\mathrm{Nd})$ isotopes are used as tracers of biogeochemical processes, water mass transport and mixing in the modern ocean ${ }^{1-4}$ (and references therein) and as paleoproxies for past oceanic circulation patterns ${ }^{5,6}$ (and references therein). Dissolved and particulate river inputs of REEs to the oceans were recognized early on as being potentially important $^{7-9}$. Later studies found the dissolution of continental atmospheric dust to be an additional REE source ${ }^{10-13}$. A marine $\mathrm{Nd}$ box model indicated, however, that to explain both global marine dissolved $\mathrm{Nd}$ concentrations and $\varepsilon \mathrm{Nd}$, a large additional $\mathrm{Nd}$ source to the oceans was required ${ }^{14}$. The model study suggested that this source originated from the ocean margins and that it was on the order of $8,000 \mathrm{Mg}$ per year. Using a general ocean circulation model that included the marine $\mathrm{Nd}$ cycle ${ }^{15}$, it was estimated that the release of $1-3 \%$ of the annual sedimentary $\mathrm{Nd}$ flux to continental margins, together with continuous dissolved/particle exchange with depth through the oceanic water column, are required to explain both the variations in global marine $\mathrm{Nd}$ concentrations and $\varepsilon \mathrm{Nd}$. Two different $\mathrm{Nd}$ general ocean circulation models indicated the missing $\mathrm{Nd}$ flux to be on the order of 11,000 and $5,500 \mathrm{Mg}$ per year ${ }^{15,16}$. However, while the potential processes governing this sediment REE release have been discussed or hypothesized, their relative importance has not. These processes include estuarine transformations of the river solid discharge ${ }^{17-20}$, boundary exchange processes directly involving the sediments deposited on the margins and/or submarine groundwater discharge ${ }^{21-25}$.

Estuaries are important biogeochemical reactors where river fluxes of inorganic and organic matter influence the chemistry and biology of coastal waters and ultimately the open oceans. It is well-known that the flocculation of river-dissolved organic matter by sea salt drives the non-conservative behaviour of trace metals in estuaries 26,27 . Early studies on the REE showed $70 \% \mathrm{Nd}$ removal in the Gironde estuary and $88 \% \mathrm{Nd}$ removal in the Great Whale estuary ${ }^{7,28}$. A landmark study by Sholkovitz ${ }^{29}$ showed that $0.22-\mu \mathrm{m}$ filtered REE concentrations also behave nonconservatively in the salinity gradient of the Amazon estuary. In the 0-6.6 salinity range, $>90 \%$ of REE were removed from solution. This removal was attributed to coagulation of riverine colloids. Surprisingly, this study showed that all REE concentrations slightly increase again in the salinity range between 6.6 and 34.4. This was interpreted as being due to the release of REE from sediments and resuspended particles. An alternative explanation was the possibility of a certain amount of spatial and temporal (on a timescale of hours to days) heterogeneity in REE concentrations of the Amazon River plume as it mixes with seawater. Multiple studies have documented REE removal in estuaries and a REE concentration rebound at mid- to high-salinities ${ }^{9,30}$. Goldstein and Jacobson ${ }^{31}$ recognized early on that estuarine REE removal is important in balancing marine REE budgets. They also documented that the $\varepsilon \mathrm{Nd}$ of dissolved and suspended river loads can differ by up to four units, and that replacing one with the other in river $\varepsilon \mathrm{Nd}$ budgets is not trivial.

Here we present results obtained within the framework of the AMANDES 3 campaign to the Amazon estuary (Fig. 1).We use filtration, ultrafiltration and $\mathrm{Nd}$ isotope analysis to reassess REE dynamics in the Amazon estuary salinity gradient and its impact on the river Nd flux to the Atlantic Ocean. We also use radium isotopes to provide constraints on the timescale of estuarine REE dynamics. We find that $\mathrm{Nd}$ release from Amazon river suspended sediments is rapid, and larger than the dissolved $\mathrm{Nd}$ river input to the Atlantic Ocean. We estimate that on a global scale the release process may dominate all other $\mathrm{Nd}$ inputs.

\section{Results}

REE behaviour in the Amazon estuary. The suspended particulate matter (SPM) $\mathrm{Nd}_{\mathrm{SPM}}$ and dissolved $\mathrm{Nd}_{<0.45 \mu \mathrm{m}}$ concentrations of the Amazon River endmember in April 2008 were $2,627 \mathrm{ng} \mathrm{kg}^{-1}$ and $123 \mathrm{ng} \mathrm{kg}^{-1}$, respectively (Supplementary Table 1). Within the dissolved phase, we find that coarse colloidal REE (defined here as $10 \mathrm{kDa}<\mathrm{REE}<0.45$ $\mu \mathrm{m})$ dominates REE speciation with $\mathrm{Nd}_{<10 \mathrm{kDa}}$ of $22.5 \mathrm{ng} \mathrm{kg}^{-1}$ and $\mathrm{Nd}_{<1 \mathrm{kDa}}$ of $2.4 \mathrm{ng} \mathrm{kg}^{-1}$. Taken together, the filtration and ultrafiltration observations suggest that $95 \%$ of Amazon River Nd is in the particulate form when it enters the Amazon estuary. Of the remaining $5 \%$ of dissolved $\mathrm{Nd}_{<0.45 \mu \mathrm{m}}, 4.9 \%$ is present in the colloidal fraction $>1 \mathrm{kDa}$ (Fig. $2 \mathrm{a}$ ). Barroux et al. ${ }^{32}$ studied the seasonal variations in dissolved $(<0.2 \mu \mathrm{m}) \mathrm{REE}$ concentrations at Óbidos and reviewed all earlier published Amazon River REE data. Dissolved $\mathrm{Nd}_{<0.2 \mu \mathrm{m}}$ varied between $47 \mathrm{ng} \mathrm{kg}^{-1}$ to $178 \mathrm{ng} \mathrm{kg}^{-1}$, during the low to high water stages from 2003 to 2005. $\mathrm{Nd}_{<0.2 \mu \mathrm{m}}$ was shown to correlate significantly with the

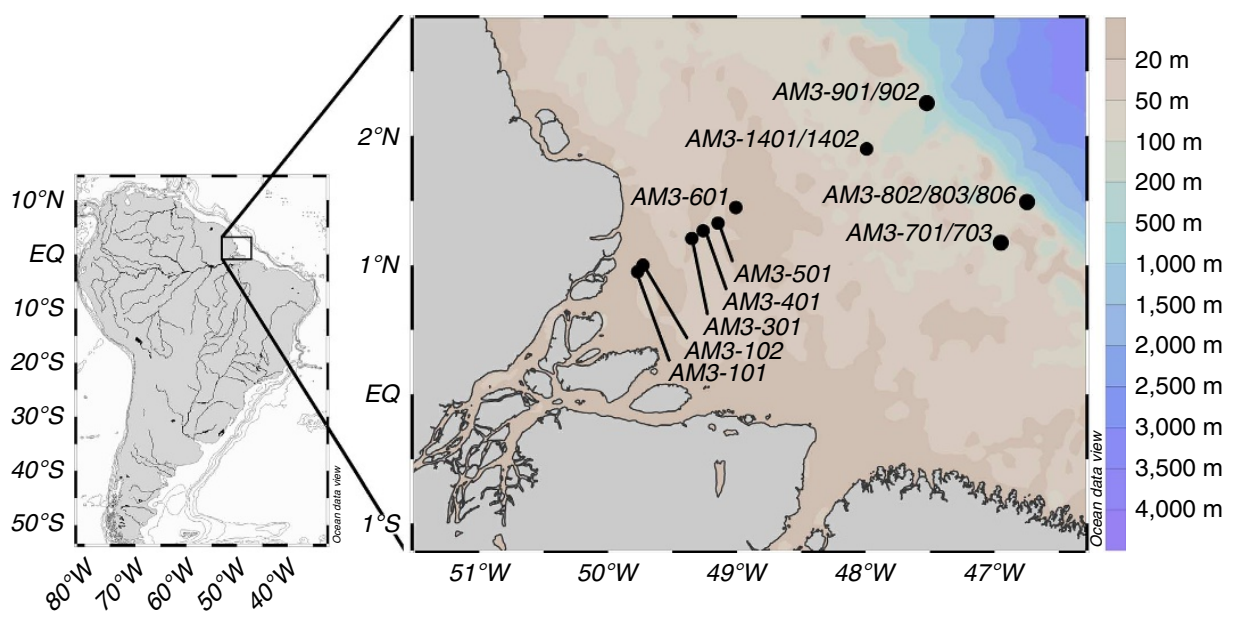

Figure 1 | Sampling stations of the AMANDES 3 cruise in the Amazon River estuary. The AMANDES 3 campaign was realized between the 6 April 2008 and the 18 April 2008 on the R/V ANTEA in the Amazon estuary shelf as part of the GEOTRACES programme. Surface samples were collected within the salinity gradient and depth profiles were obtained near the break of the shelf. 

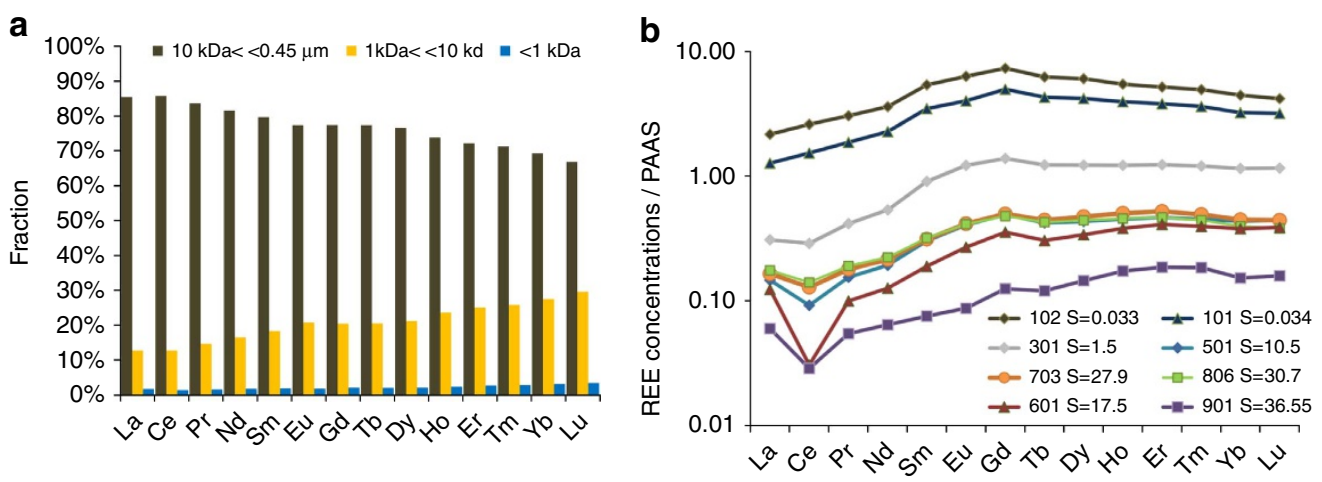

Figure 2 | Dissolved REE speciation and total dissolved REE patterns across the Amazon estuary salinity gradient. (a) Operational REE speciation within the dissolved fraction $(<0.45 \mu \mathrm{m})$ for the Amazon River endmember (this work). LREE are enriched in the coarse colloidal fraction $(10 \mathrm{kDa}<\mathrm{REE}<0.45 \mu \mathrm{m})$ in comparison to the fine colloidal $(1 \mathrm{kDa}<\mathrm{REE}<10 \mathrm{kDa})$ fraction and the 'truly dissolved' $<1 \mathrm{kDa}$ fraction. (b) Post-Archean Australian shale (PAAS) normalized dissolved REE concentration along the Amazon estuary transect. The PAAS normalized Amazon River REE pattern loses its typical MREE enrichment ${ }^{2,29}$ by colloid coagulation, and evolves towards a HREE-enriched pattern that is more similar to Atlantic Ocean water.

discharge of the Amazon River (eqs. (1), $\mathrm{r} 2=0.64$ ):

$$
\mathrm{Nd}_{<0.2 \mu \mathrm{m}}=7 \times 10^{-4} \times D-9.6
$$

where $D$ represents the discharge in $\mathrm{m}^{3} \mathrm{~s}^{-1}$. The Amazon discharge at the time of our observation in 2008 was $234,300 \mathrm{~m}^{3} \mathrm{~s}^{-1} \quad$ (http://www.ore-hybam.org). Using this relationship we estimated a $\mathrm{Nd}_{<0.2 \mu \mathrm{m}}$ concentration at Obidos of $154 \pm 40 \mathrm{ng} \mathrm{kg}^{-1}$ (1 s.d.), which is similar to our $\mathrm{Nd}_{<0.45 \mu \mathrm{m}}$ observation of $123 \mathrm{ng} \mathrm{kg}^{-1}$. The TTO/TAS 44 Amazon river endmember samples 44 and 46 collected during the low water stage in December 1982 and reported in the study by Piepgras and Wasserburg ${ }^{2}$ displayed dissolved Nd concentrations of 53.9 and $48.5 \mathrm{ng} \mathrm{kg}^{-}{ }^{-1}$, these values being also consistent with the seasonal dissolved $\mathrm{Nd}$ variation. Amazon River endmember normalized REE patterns in the different dissolved sub-phases show a light rare earth elements (LREE) enrichment in the coarse colloidal fraction compared with the fine colloidal fraction (defined here as $1 \mathrm{kDa}<\mathrm{REE}<10 \mathrm{kDa}$ ) and the truly dissolved phase $(<1 \mathrm{kDa}$; Fig. 2a). This feature is in agreement with a laboratory mixing experiment using Connecticut River particles and water ${ }^{19}$. Within the colloidal fraction the main REE carriers are thought to be humic acids as well as iron and manganese oxyhydroxides whereas within the truly dissolved fraction, the main ligands that complex REE are carbonate ions and organic compounds that pass through the $1 \mathrm{kDa}$ membrane such as fulvic acids $^{33}$.

Detailed observations of the Amazon Estuary obtained during the AmasSeds 1 campaign illustrated the so called colloidal flocculation for the REE ${ }^{29}$. The fraction of REEs that are removed from the dissolved phase in the salinity gradient must be calculated relative to the REE concentrations in the river endmember. Sholkovitz ${ }^{29}$ noted that the lowest AmasSeds 1 salinity samples (0.3) taken on 4-10 August 1989, and which have $\mathrm{Nd}$ concentrations of 83.5 and $67.9 \mathrm{ng} \mathrm{kg}^{-1}$, do not represent the true river endmember. Using equation (1) and the Amazon discharge at this time in $1989\left(237,814 \mathrm{~m}^{3} \mathrm{sec}^{-1}\right)$ yields corresponding Nd concentration at Obidos of $157 \pm 40 \mathrm{ng} \mathrm{kg}^{-1}$. Figure $3 \mathrm{a}$ shows the $\mathrm{Nd}$ concentration gradient observed during both AmasSeds 1 and Amandes 3 campaign (this study and the study by Sholkovitz ${ }^{29}$ ). Similar to Sholkovitz observations, we find that total dissolved $\mathrm{Nd}<0.45 \mu \mathrm{m}$ concentrations rapidly decrease in the low-salinity region $(0-10)$ from $123 \mathrm{ng} \mathrm{kg}^{-1}$ to a minimum of $4.3 \mathrm{ng} \mathrm{kg}^{-1}$. Using the estimated river endmember of $157 \mathrm{ng} \mathrm{kg}^{-1}\left(1.1 \pm 0.3 \mu \mathrm{mol} \mathrm{kg}^{-1}\right)$ and the observed $\mathrm{Nd}$ minima of $3.8 \mathrm{ng} \mathrm{kg}^{-1}\left(26.3 \mathrm{pmol} \mathrm{kg}^{-1}\right)$ for the AmasSeds I campaign, both the Sholkovitz ${ }^{29}$ and this study show that $>90 \%$ of dissolved $\mathrm{Nd}$ was removed from solution at the first stages of the Amazon Estuary. The dissolved Nd removal is strongest at a salinity of 17.5, a value which is higher than the AmasSeds 1 study (6.6) (Fig. 3a). This feature could be due to the use of different filter pore sizes in the two studies (that is, $0.45 \mu \mathrm{m}$ here versus $0.22 \mu \mathrm{m}$ during AmasSed) but more likely represents true natural variability, possibly related to seasonality (AmasSeds- 1 in August 1989; Amandes-3 in April 2008). We observe that 98\% of Amazon River Nd is in the $>1 \mathrm{kDa}$ colloidal fraction, and that the fine colloidal $\mathrm{Nd}_{<10 \mathrm{kDa}}$ fraction gradually increases from the river endmember to the seawater endmember (that is, $18 \%, 53 \%$, $73 \%$ and $90 \%$ for salinities $0.03,1.5,10.5$ to 34.9 respectively, Supplementary Table 1). This trend confirms that large REE carrying colloids (between $10 \mathrm{kDa}$ and $0.45 \mu \mathrm{m}$ ) flocculate out of solution along the estuarine mixing gradient as illustrated in Supplementary Fig. 1.

For salinities $>17.5$, dissolved REE concentrations slightly increase again, as also shown in previous studies ${ }^{29}$ (Fig. 3a). REE removal in the low-salinity zone is more pronounced for the LREE than the heavy rare earth elements (HREE), and REE release in the mid- to high-salinity zone is characterized by a slight preferential release of LREE to the dissolved $\mathrm{Nd}_{<0.45 \mu \mathrm{m}}$ pool (Fig. 2b, Supplementary Fig. 2a,b). Consequently, the shalenormalized Amazon River REE pattern loses its typical middle rare earth element (MREE) enrichment ${ }^{2,29}$ by colloid coagulation, and evolves towards a HREE-enriched pattern that is more similar to Atlantic Ocean water (Fig. 2b).

Determination of apparent water ages using $\mathrm{Ra}$ isotopes. Radium ( $\mathrm{Ra}$ ) has four radioactive isotopes that display different half-lives $\left({ }^{224} \mathrm{Ra}, 3.66\right.$ days; ${ }^{223} \mathrm{Ra}, 11.4$ days; ${ }^{228} \mathrm{Ra}, 5.75$ years; ${ }^{226} \mathrm{Ra}, 1,600$ years). Ra isotopes can thus be used as clocks at different space and time scales. In freshwater, $\mathrm{Ra}$ is bound to suspended particles. Ra is then released into the dissolved phase once the freshwater enters in contact with seawater, due to the increased ionic strength ${ }^{34,35}$. The release of Ra isotopes to the dissolved phase allows us to use Ra isotopes as a tool to study the rate of water transport ${ }^{36,37}$. In this work, we determined apparent $\mathrm{Ra}$ ages for the water bodies investigated along the Amazon River plume, using the ${ }^{224} \mathrm{Ra} /{ }^{223} \mathrm{Ra}$ ratio as a clock. The ${ }^{224} \mathrm{Ra} /{ }^{223} \mathrm{Ra}$ ratio determined in each water sample is thus compared with the initial ratio determined at station AM3-0101 to derive an apparent age. The apparent ages of the water bodies increase as 
a

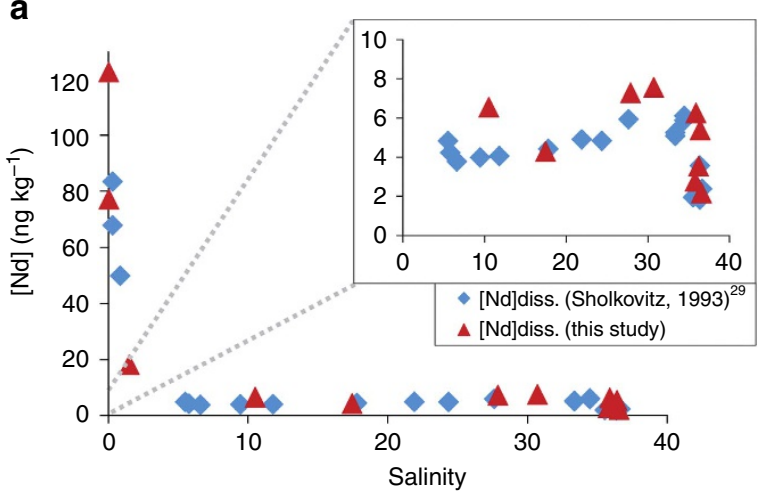

b

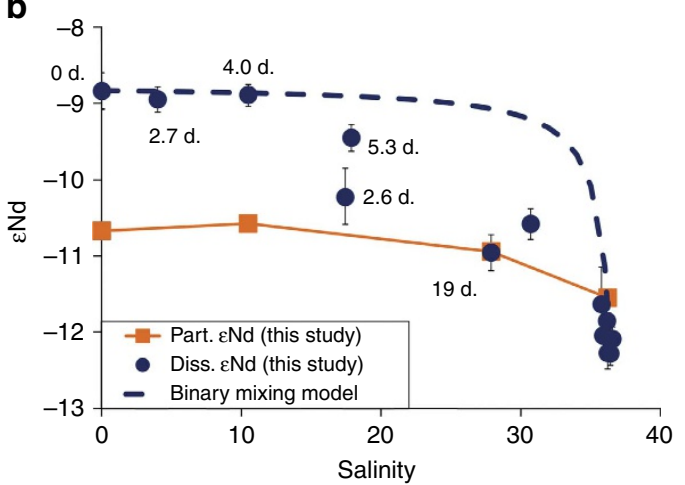

Figure 3 | REE concentrations and Nd isotopic composition in the

Amazon River estuary. (a) Amazon estuary Nd versus salinity gradient in the dissolved fraction in the study by Sholkovitz ${ }^{29}$ (blue diamonds), and this study (red triangles). (b) Amazon estuary $\varepsilon N d$ versus salinity in the dissolved (blue dots) and particulate (orange squares) fractions; the theoretical dissolved $\mathrm{Nd}$ conservative mixing curve is shown (blue-dashed line). The apparent radium ages estimated for the different water samples (expressed in days) are also reported.

the Amazon plume moves towards offshore (Fig. 3b). We use these ages to estimate the rate of the $\mathrm{Nd}$ release that takes place within the Amazon plume that enters into the Atlantic Ocean.

\&Nd behaviour in the Amazon estuary. The $\mathrm{Nd}$ isotopic composition of Amazon River SPM $(>0.22 \mu \mathrm{m})$ has been reviewed elsewhere ${ }^{38}$, based on monthly $\varepsilon \mathrm{Nd}_{\mathrm{SPM}}$ observations for Solimões and Madeira tributaries, which are the two main SPM carriers in the Amazon basin. It was observed that $\varepsilon N d$ of Solimoes SPM $(-8.9$ to -9.9$)$ is slightly more radiogenic than $\varepsilon N d$ of Madeira SPM $(-10.8$ to -12.1$)$. We calculate, by weighting the seasonal $\varepsilon N d$ variations by Solimoes and Madeira SPM concentrations and discharge that Amazon River SPM should have an annual mean $\varepsilon \mathrm{Nd}$ of -10.6 . This estimate is based on samples collected $>1,500 \mathrm{~km}$ from the estuary, yet in good agreement with the $\varepsilon \mathrm{Nd}$ of $-10.7 \pm-0.1(>0.45 \mu \mathrm{m})$ analysed in this study for the estuarine Amazon River endmember (sample AM3-0102).

The dissolved phase $\varepsilon \mathrm{Nd}$ for the Amazon River endmember was determined during the Transient Tracers in the Ocean study (TTO/TAS) at stations 44 and 46, sampled in December 1982 in the mouth of the Amazon River. $\varepsilon N d$ of $-8.4 \pm 0.5$ and $-9.2 \pm 0.4$ were observed ${ }^{39}$. $\varepsilon N d$ of $-8.9 \pm 0.5$ was also reported in a subsequent study ${ }^{2}$. The dissolved phase $\varepsilon \mathrm{Nd}$ of $-8.8 \pm 0.2$ that we observe for the Amazon River endmember in this study (AM3-0102) is in excellent agreement with these earlier data. The offset that we observe between particulate and dissolved $\varepsilon N d$ in the Amazon River endmember suggests that a large fraction of the riverine particulate $\mathrm{Nd}$ is not exchangeable.

Figure $3 \mathrm{~b}$ shows the evolution of $\varepsilon \mathrm{Nd}$ in the dissolved and particulate phases within the Amazon estuary salinity gradient. The apparent ages of the water bodies determined using radium isotopes-defined as the time elapsed since the river endmember entered in contact with seawater-are also reported for each water sample. Throughout the low-salinity region (0-17.5), as total dissolved $\mathrm{Nd}_{<0.45 \mu \mathrm{m}}$ decreases from 123 to $6.6 \mathrm{ng} \mathrm{kg}^{-1}$, $\varepsilon \mathrm{Nd}_{<0.45 \mu \mathrm{m}}$ remains constant at $-8.9 \pm 0.1$ (s.d., $n=3$ ). This suggests that $\varepsilon \mathrm{Nd}_{<0.45 \mu \mathrm{m}}$ is uniform and exchangeable between the truly dissolved and colloidal pools. At salinities higher than 17.5 , when $\mathrm{Nd}_{<0.45 \mu \mathrm{m}}$ reaches its minimum of $4.3 \mathrm{ng} \mathrm{kg}^{-1}$ and then increases to $6-7 \mathrm{ng} \mathrm{kg}^{-1}$, we observe a gradual decrease in $\varepsilon \mathrm{Nd}_{<0.45 \mu \mathrm{m}}$ down to -11.0 . This latter pattern is observed in water bodies displaying an apparent radium age of 19 days. Although the Atlantic Ocean endmember that mixes with Amazon River water has a low $\varepsilon N d_{<0.45 \mu \mathrm{m}}$ of about -12.1 , conservative mixing of Amazon and marine $\mathrm{Nd}$ alone is not sufficient to explain the $\varepsilon \mathrm{Nd}_{<0.45 \mu \mathrm{m}}$ gradient in the Amazon estuary, let alone the increase in total dissolved $\mathrm{Nd}$ in the mid-salinity region. The lower $\varepsilon N d$ of the $\mathrm{Nd}_{\mathrm{SPM}}$ released into the dissolved phase also indicates that it unlikely originates from desorption of exchangeable $\mathrm{Nd}_{\mathrm{SPM}}$ bound to recently coagulated colloids or particulate organic carbon in SPM, as these should have an $\varepsilon N d$ close to dissolved $\mathrm{Nd}(-8.9)$. We observed that Amazon estuary SPM has an average $\varepsilon \mathrm{Nd}$ of -10.7 . This pattern therefore suggests that the release of a small fraction of particulate lithogenic $\mathrm{Nd}$ is responsible for the decrease in $\varepsilon \mathrm{Nd}$ of total dissolved $\mathrm{Nd}$ at salinity $>17.5$.

\section{Discussion}

It is of interest to discuss whether the mechanism of $\mathrm{Nd}_{\mathrm{SPM}}$ release is desorption of SPM-bound $\mathrm{Nd}$, or dissolution of Nd-containing SPM solid phases. Two lines of evidence argue for a dissolution mechanism. First, if $\mathrm{Nd}_{\mathrm{SPM}}$ on mixing with seawater were to be desorbed from binding sites on particulate organic matter or $\mathrm{Fe}$ and $\mathrm{Mn}$ oxyhydroxide surfaces, the $\mathrm{Nd}$ would have to be per definition exchangeable. Exchangeable $\mathrm{Nd}_{\text {SPM }}$ would then have to have a uniform $\varepsilon N d$ between the river water dissolved and releasable $\mathrm{Nd}_{\mathrm{SPM}}$ pools. Uniform $\varepsilon \mathrm{Nd}$ is not what we observe. Second, we see a decoupling between the release of $\mathrm{Ra}_{\mathrm{SPM}}$ and $\mathrm{Nd}_{\mathrm{SPM}}$ along the salinity gradient, $\mathrm{Ra}$ being released in the $0-5$ salinity range, whereas $\mathrm{Nd}$ is released at higher salinity (ca. 17.5). This suggests that two different mechanisms are at play. The rapid release of $\mathrm{Ra}$ when the freshwater enters in contact with seawater is known to be associated with the desorption of $\mathrm{Ra}$ from $\mathrm{SPM}^{34,36}$. The release of $\mathrm{Nd}_{\mathrm{SPM}}$ at higher salinity may suggest a slower process assuming that the chemical reactions that promote such release have also started when the freshwater enters in contact with seawater. The observed release of $\mathrm{Nd}_{\mathrm{SPM}}$ in the salinity gradient may thus be mostly driven by dissolution processes, rather than by desorption.

We apply an isotope mass balance to quantify the fraction of $\mathrm{Nd}$ that is released from SPM along the estuarine gradient (see Methods). Three major dissolved Nd fractions are defined in the estuarine gradient relative to total dissolved $\mathrm{Nd}$ : the remaining Amazon River fraction, $f_{\text {Ama; }}$ the fraction from the Atlantic seawater endmember, $f_{\mathrm{Att}}$; and the fraction released from SPM, $f_{\text {SPM. }}$. We assume that the three dissolved $\mathrm{Nd}$ fractions have corresponding $\varepsilon \mathrm{Nd}_{\mathrm{Ama}}, \varepsilon \mathrm{Nd}_{\mathrm{Atl}}$ and $\varepsilon \mathrm{Nd}_{\mathrm{SPM}}$ of $-8.8,-12.1$ and -10.7 , respectively. The fraction of $\mathrm{Nd}$ released from sediments becomes significant at a salinity of 17.5 . We calculate that in the salinity ranges of $0-10,17.5$ and $28-30$ (corresponding to our samples) $\sim 0,1.5$ and $4.9 \pm 1.2$ (s.d.) ng of $\mathrm{Nd}$ per $\mathrm{kg}$ of estuarine 
water has been released from SPM, respectively (Supplementary Table 2). The quoted uncertainty (s.d.) is based on averaging over two samples that define the $28-30$ salinity range. To evaluate the magnitude of the $4.9 \mathrm{ng} \mathrm{kg}^{-1} \mathrm{Nd}$ released at salinity $28-30$, we need to correct this value for dilution with seawater. The resulting concentration of $24.7 \pm 6.0 \mathrm{ng} \mathrm{kg}^{-1}$ of $\mathrm{Nd}_{\mathrm{SPM}}$ released at ' 0 ' salinity can now be compared with the particulate $\mathrm{Nd}_{\mathrm{SPM}}$ concentration in the Amazon River in April 2008 (that is, $2,600 \pm 260 \mathrm{ng} \mathrm{kg}^{-1}$, rounded off to two significant figures). We calculate that approximately $0.94 \% \pm 0.25 \%$ (propagated s.d.) of particulate Amazon River $\mathrm{Nd}_{\mathrm{SPM}}$ was released to the dissolved $\mathrm{Nd}$ pool in the estuary.

The Amazon River-dissolved Nd flux to the Atlantic Ocean can be summarized based on the detailed seasonal REE observations by Barroux et al. ${ }^{32}$ and assuming that our observed $\mathrm{Nd}$ removal and Nd release are constant throughout the year: $93 \%$ of the annual $607 \mathrm{Mg}$ per year $\mathrm{Nd}_{<0.45 \mu \mathrm{m}}$ flux ${ }^{32}$ is removed by colloid coagulation in the low-salinity zone, transferring the remaining $7 \%$, that is, $42 \mathrm{Mg}$ per year to the Atlantic Ocean. Here we estimate that $0.94 \%$ of the annual $19,800 \mathrm{Mg}$ per year $\mathrm{Nd}_{\mathrm{SPM}}$ flux (based on a $\mathrm{Nd}_{\mathrm{SPM}}$ of $33 \mathrm{mg} \mathrm{kg}^{-1}$ (ref.8) and Amazon sediment discharge of $610^{14} \mathrm{~g} \mathrm{y}^{-1}$ (ref. 40)) is released from SPM in the mid- to high-salinity zone, that is, $186 \mathrm{Mg}$ per year. The $\mathrm{Nd}$ release from SPM is therefore approximately four times larger than the dissolved Nd river flux to the Atlantic Ocean. The typical MREE enriched pattern of the Amazon River-dissolved pool is thus near-quantitatively removed to SPM and sediments in the salinity gradient and replaced by a HREE-enriched pattern that derives from the partial dissolution of SPM and approaches that of Atlantic Ocean waters (Fig. 2b).

In the following we compare our observations to published estuarine REE studies and examine the implications of $\mathrm{Nd}_{\mathrm{SPM}}$ release on the transfer of $\mathrm{Nd}$ globally. Table 1 summarizes published observations of estuarine dissolved $\mathrm{Nd}$ dynamics, $\mathrm{pH}$, SPM and dissolved organic carbon (DOC). Figure 4a,b shows all published estuarine $\mathrm{Nd}_{<0.45 \mu \mathrm{m}}$ concentration trends, normalized

\section{Table 1 | Summary of published studies on estuarine $\mathbf{N d}$ dynamics.}

\begin{tabular}{|c|c|c|c|c|c|}
\hline River & $\begin{array}{c}\text { Dissolved } \\
\text { Nd } \\
\text { ng kg }^{-1}\end{array}$ & pH & $\mathrm{DOC} \mathrm{mg} \mathrm{I}^{-1}$ & $\begin{array}{c}\text { Nd } \\
\text { removal } \\
\%\end{array}$ & Reference \\
\hline Amazon & 157 & 6.9 & 5.1 & 97 & 29 \\
\hline Amazon & 123 & 6.9 & 5.1 & 93 & This study \\
\hline Fly & 26 & 7.8 & 3.2 & 87 & 30 \\
\hline Sepik & 36 & 7.3 & 3.4 & 81 & 30 \\
\hline Gironde & 38 & 7.7 & 3.1 & 68 & 7 \\
\hline Luce & 53 & 4.5 & 9.0 & 73 & 53 \\
\hline Elimbah Creek & 103 & 6.1 & & 79 & 52 \\
\hline $\begin{array}{l}\text { Chao Phraya } \\
\text { river-July }\end{array}$ & 14 & 7.0 & & 49 & 51 \\
\hline $\begin{array}{l}\text { Chao Phraya } \\
\text { river- } \\
\text { November }\end{array}$ & 14 & 7.0 & & 58 & 51 \\
\hline Great Whale & 167 & 6.8 & 5.3 & 66 & 28 \\
\hline Vora Creek & 177 & 4.4 & 12.8 & & 52 \\
\hline Vora Creek & 165 & 4.6 & 9.8 & & 54 \\
\hline Connecticut & 357 & 7.0 & 3.2 & 56 & 55 \\
\hline Delaware & 26 & 7.5 & 2.6 & 70 & 55 \\
\hline Mullica & 412 & 4.6 & & 81 & 55 \\
\hline Tamar Springs & 37 & 7.25 & & 65 & 55 \\
\hline Tamar neaps & 33 & 7.25 & & 40 & 55 \\
\hline
\end{tabular}

DOC, dissolved organic carbon; Nd, neodymium

River endmember dissolved $\mathrm{Nd}$ is shown, and maximum $\mathrm{Nd}$ removal was calculated as the strongest drop in $\mathrm{Nd}$ along the estuarine transect, after correcting for mixing with seawater. Mean Nd removal is $71 \pm 16 \%$ (s.d.). to the corresponding river water $\mathrm{Nd}_{<0.45 \mu \mathrm{m}}$. All studies show a pronounced removal of $\mathrm{Nd}_{<0.45 \mu \mathrm{m}}$ in the low-salinity range $(0-10)$ that is thought to represent REE-carrying colloid coagulation $^{9,20,31}$. Two types of patterns can be observed in the mid to high salinity range (10-36): a gradual decrease in $\mathrm{Nd}_{<0.45 \mu \mathrm{m}}$ to concentrations that are close to the seawater endmember (Fig. 4a), or a decrease in $\mathrm{Nd}_{<0.45}$ um followed by a more or less pronounced increase in $\mathrm{Nd}_{<0.45 \mu \mathrm{m}}$ (Fig. $4 \mathrm{~b}$ ). On the basis of our $\varepsilon N d$ observations in the Amazon estuary, we argued above that the $\mathrm{Nd}_{<0.45 \mu \mathrm{m}}$ rebound is due to dissolutive $\mathrm{Nd}$ release from SPM. Apart from a dilution due to mixing, Amazon estuary $\mathrm{Nd}$ dynamics appear therefore to be controlled by two competing mechanisms: a decrease in $\mathrm{Nd}_{<0.45 \mu \mathrm{m}}$ due to colloid coagulation, and an increase in $\mathrm{Nd}_{<0.45 \mu \mathrm{m}}$ due to SPM dissolution. The relative magnitude of $\mathrm{Nd}$ removal and release likely depend on SPM mineralogy, river $\mathrm{pH}, \mathrm{DOC}$ and major elements, amongst others. We illustrate in Fig. 4c,d how natural variations in $\mathrm{Nd}$ removal and release can result in observed estuarine Nd trends that cover most published observations. For example, rapid and pronounced Nd removal (Fly and Amazon) is more likely to reveal the dissolutive $\mathrm{Nd}_{\mathrm{SPM}}$ release at mid-high salinities (Fig. 4c). Slower Nd removal in combination with identical $\mathrm{Nd}_{\mathrm{SPM}}$ release may visually hide the $\mathrm{Nd}$ rebound in observations (Fig. 4d). In this latter case $\mathrm{Nd}$ isotopes may be useful to quantitatively discern the two processes.

Goldstein and Jacobson ${ }^{31}$ examined early studies on estuarine $\mathrm{Nd}_{<0.45 \mu \mathrm{m}}$ removal to identify the controlling river chemistry parameters. They postulated that low $\mathrm{pH}$, high Nd rivers should show more Nd removal. The two available studies on the Gironde (low $\mathrm{Nd},{ }^{7}$ ) and Great Whale (high $\mathrm{Nd}^{28}$ ), however, showed similar $\mathrm{Nd}$ removal of $\sim 70 \%$. This removal factor has subsequently become the benchmark value in marine $\mathrm{Nd}$ models $\left({ }^{14-16}\right)$. We calculated maximum $\mathrm{Nd}_{<0.45 \mu \mathrm{m}}$ removal for the 15 estuarine transects (Table 1). The percentage $\mathrm{Nd}_{<0.45 \mu \mathrm{m}}$ removal data are normally distributed, with a mean and s.d. of $71 \pm 16 \%$. Nd removal is not correlated with $\mathrm{pH}$ $\left(r^{2}=0.03\right)$, or with DOC $\left(r^{2}=0.02\right)$, suggesting that the historically used nominal $70 \% \mathrm{Nd}$ removal value ${ }^{31}$ can be used for rivers globally. Future work should assess $\mathrm{Nd}_{\mathrm{SPM}}$ release $\%$ for a large number of estuaries by examining dissolved and SPM Nd concentration and $\varepsilon N d$ gradients.

The implication of our findings for the global marine $\mathrm{Nd}$ budget can at this point only be assessed from our single Amazon estuary observation of $\mathrm{Nd}_{\mathrm{SPM}}$ release. We use a global riverine sediment flux to the oceans of $1.85 \pm 0.1610^{16} \mathrm{~g}$ per year ${ }^{41-44}$. Mean river $\mathrm{Nd}_{\text {SPM }}$ concentrations are $33 \pm 12 \mu \mathrm{gg}^{-1}$ (ref. 21) and we observe in this study that $0.94 \pm 0.25 \%$ of river $\mathrm{Nd}_{\mathrm{SPM}}$ is released on mixing with seawater. We thus estimate that globally $5,700 \pm 2,600 \mathrm{Mg}$ of $\mathrm{Nd}$ (s.d. by error propagation; rounded off to two significant figures) is released annually to coastal marine waters. The estimated range of $3,100-8,300 \mathrm{Mg}$ per year is 6-17 times larger than the $500 \mathrm{Mg}$ per year dissolved river-Nd load ${ }^{31}$ (taking into account the globally observed $70 \%$ estuarine removal). It is also $8-21$ times larger than the atmospheric dust $\mathrm{Nd}$ flux, assuming $2 \%$ dust dissolution, of $400 \mathrm{Mg}$ per year ${ }^{14}$. The $\mathrm{Nd}$ release range overlaps with the model estimated missing $\mathrm{Nd}$ flux of 5,500-11,000 Mg per year, but may still be up to 3.5 times smaller, based on the lower observed $(3,100)$ and upper modelled $(11,000)$ extremes.

Using radium isotopes to constrain the timescale of the chemical reactions taking place on Amazon River water mixing with seawater, we can further argue that coagulation and Nd-release processes occur rapidly, within $\sim 19$ days ( $3 \pm 1$ weeks). The magnitude and timing of $\mathrm{Nd}$ release from sediments observed in this study is therefore also coherent with batch experiments where basaltic lithogenic particles of diverse origins were incubated with seawater ${ }^{17}$. 
a

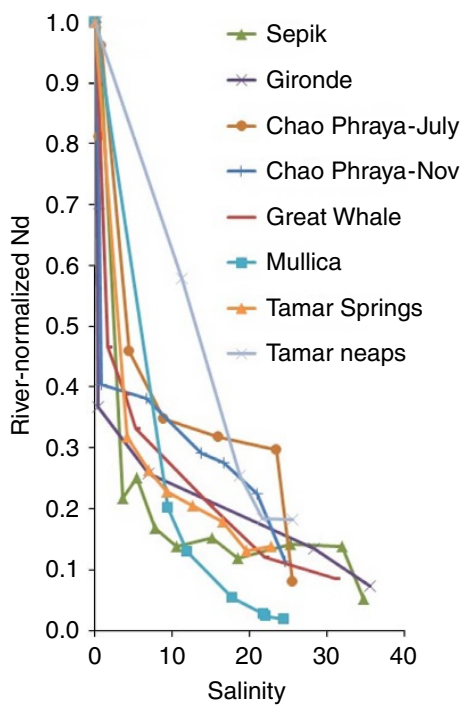

b

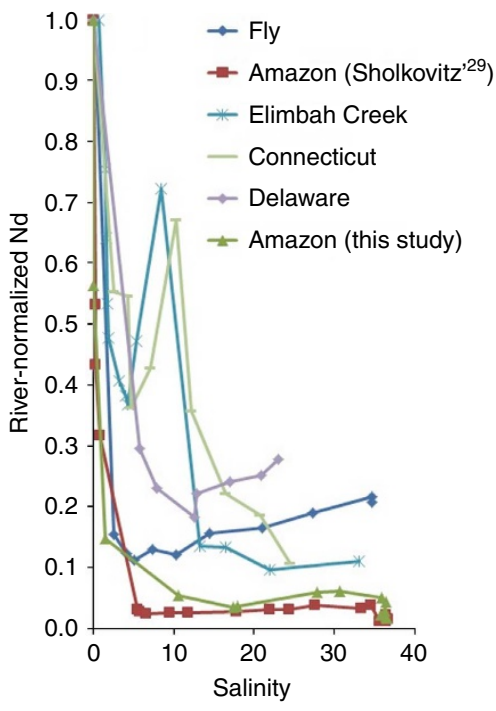

c
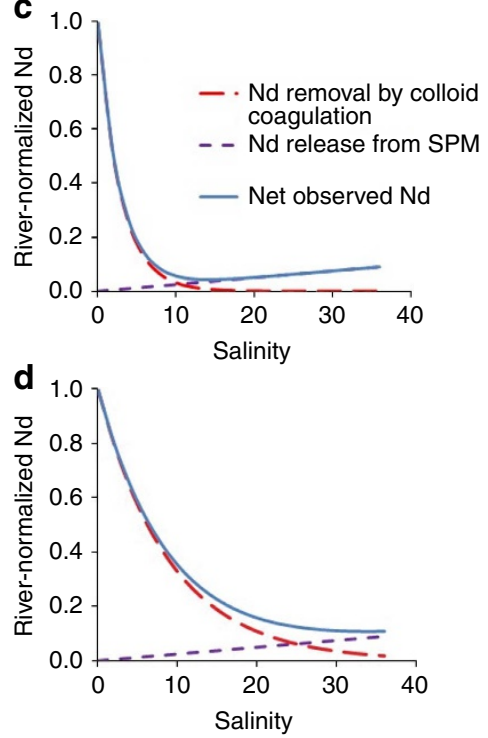

Figure 4 | Overview of published estuarine dissolved Nd observations. In this overview of published estuarine dissolved Nd observations ${ }^{7,9,28-30,51-55}$ all $\mathrm{Nd}$ concentrations are normalized to that of the corresponding river endmember. (a) estuaries that show a gradual drop in Nd concentrations, (b) estuaries that show both an initial drop (removal) followed by a rebound (release) in Nd concentrations, (c) scenario illustrating simultaneous fast Nd removal and slow Nd release, (d) scenario illustrating simultaneous slow Nd removal and slow $\mathrm{Nd}$ release. The removal and release scenarios in $\mathbf{c}$ and $\mathbf{d}$ correspond to the observed trends in $\mathbf{a}$ and $\mathbf{b}$, respectively.

In summary, our observations suggest that dissolved REE have little influence on the $\mathrm{Nd}$ isotopic composition of the Amazon plume and the Atlantic Ocean. Rather, the release of REE from suspended river sediments dominates REE concentrations and $\varepsilon N d$ of the Amazon River plume over the northeast Brazilian shelf. The large amount of Nd released from lithogenic suspended sediments carried by the Amazon River over limited space and time scales underlines that river sediments may contribute significantly to the global marine dissolved $\mathrm{Nd}$ budget and possibly to that of other chemical elements.

\section{Methods}

Sample collection and treatment. Samples were obtained on the RV/ANTEA in April 2008 (AMANDES 3 campaign) and were collected in 8-1 Niskin bottles mounted on a 12-bottle CTD-equipped rosette. For Nd isotopic analysis, 101 were filtered on board with $0.45-\mu \mathrm{m}$ polyethersulfone (PES) Supor filters. Eight-litre aliquots (out of $10 \mathrm{l}$ ) were immediately acidified to $\mathrm{pH} 3.5$ using double-distilled $6 \mathrm{M} \mathrm{HCl}$ and 7.51 was preconcentrated onboard using two C18 SepPak cartridges loaded with a strong REE complexant ( $\left.\mathrm{HDEHP} / \mathrm{H}_{2} \mathrm{MEHP}\right)$. The remaining 0.51 acidified sample was conserved for total dissolved REE analysis. Additional onboard 10- and 1-kDa ultrafiltration, using Millipore ultrafiltration cartridges, was done on 2-l unacidified aliquots to observe in detail the REE features of the coarse REE-colloidal $(10 \mathrm{kDa}<\mathrm{REE}<0.45 \mu \mathrm{m})$, fine REE-colloidal $(<10 \mathrm{kDa}$; $>1 \mathrm{kDa})$ and truly dissolved fractions $(<1 \mathrm{kDa})$. These ultrafiltered samples were subsequently acidified using double-distilled $6 \mathrm{M} \mathrm{HCl}$.

Back at the land-based LEGOS laboratory, the REE preconcentrated on C18 cartridges were eluted using $6 \mathrm{M} \mathrm{HCl}$, evaporated and redissolved in $1.5 \mathrm{ml}$ of $1 \mathrm{M}$ $\mathrm{HCl}$. Nd separation was achieved by a two-step chromatography protocol using cationic AG50 X8 and Ln-SPEC resins. After evaporation to dryness and dissolution again in $2 \mathrm{M} \mathrm{HCl}, \mathrm{C} 18$ eluate was loaded on a cation-exchange column $(0.6 \mathrm{~cm}$ in diameter, $4.8 \mathrm{~cm}$ in height) packed with Biorad AG50W-X8 (200-400 mesh) resin to extract the REE from the remaining matrix using $\mathrm{HCl}$ and $\mathrm{HNO}_{3}$. The REE were then eluted with $6 \mathrm{ml}$ of $6 \mathrm{M} \mathrm{HCl}$. This solution was evaporated and redissolved in $0.3 \mathrm{ml}$ of $0.2 \mathrm{M} \mathrm{HCl}$ for the final extraction of $\mathrm{Nd}$ using an anion-exchange column $(0.4 \mathrm{~cm}$ in diameter, $4 \mathrm{~cm}$ in height $)$ packed with $0.5 \mathrm{ml}$ of $\mathrm{Ln}-\mathrm{Spec}$ resin. A final elution using $2.5 \mathrm{ml}$ of $0.2 \mathrm{M} \mathrm{HCl}$ allowed recovering the neodymium.

REE and $\boldsymbol{\varepsilon N d}$ analysis. Nd isotope measurements were made on a Thermo Finnigan MAT 261 at the Observatoire Midi-Pyrénées in dynamic mode, correcting for instrumental mass bias using a ${ }^{146} \mathrm{Nd} /{ }^{144} \mathrm{Nd}$ ratio of 0.7219 . Repeated analysis of the La Jolla standard gave a ${ }^{143} \mathrm{Nd} /{ }^{142} \mathrm{Nd}$ ratio of $0.511843 \pm 0.000020(2$ s.d., $n=49)$ in agreement with the recommended value of $0.511858^{45}$. Blank contributions to the $\mathrm{Nd}$ isotopic measurement were on average $<3 \%$ of the total signal. Suspended particles $(>0.45)$ samples were analysed at the Ifremer laboratory of Brest following the method described in ref. 46. The $\mathrm{Nd}$ isotope signature is defined as $\varepsilon \mathrm{Nd}$, the ratio of radiogenic ${ }^{143} \mathrm{Nd}$ over stable ${ }^{144} \mathrm{Nd}$, normalized to CHUR (Chondritic Uniform Reservoir, ${ }^{143} \mathrm{Nd} /{ }^{144} \mathrm{Nd}=0.512638$ ) on the parts per ten-thousand scale (equation (2)); which represents the present-day average earth value ${ }^{47}$ :

$$
\varepsilon \mathrm{Nd}=\left(\frac{\left({ }^{143} \mathrm{Nd} /{ }^{144} \mathrm{Nd}\right)_{\text {measured }}}{\left({ }^{143} \mathrm{Nd} /{ }^{144} \mathrm{Nd}\right)_{\mathrm{CHUR}}}-1\right) \times 10^{4}
$$

A new multiple isotope dilution-sector field ICP-MS method was used to quantify REE concentrations with a precision $<2 \%$ for most REE, except $\mathrm{La}$ and $\mathrm{Ce}<5 \%{ }^{28}$ For REE concentration analysis 500-ml sample aliquots were taken from the 10-1 $<0.45-\mu \mathrm{m}$ filtrates and $2-1$ ultrafiltration permeates. The samples were then spiked with a mix of 10 artificially enriched REE isotopes and subsequently preconcentrated by iron co-precipitation followed by AG1-X8 and AG50-X8 ion chromatography. Samples were analysed using a sector field ICP-MS (Thermo Scientific Element-XR) at Observatoire Midi-Pyrénées. Details on spiking, separation and analysis procedures can be found in ref. 48 .

Radium analysis. In parallel, $\mathrm{Ra}$ isotopes were analysed in water samples collected in the Amazon plume within the salinity gradient. Briefly, large volumes of water (up to $200 \mathrm{l}$ ) were collected and passed through cartridges filled with $\mathrm{Mn}$ fibres.

${ }^{224} \mathrm{Ra}\left(T_{1 / 2}=3.66\right.$ days $)$ and ${ }^{223} \mathrm{Ra}\left(T_{1 / 2}=11.4\right.$ days $)$ activities were determined on the ship using a Radium Delayed Coincidence Counter ${ }^{49,50}$. Following Moore ${ }^{35}$, we used the ${ }^{224} \mathrm{Ra} /{ }^{223} \mathrm{Ra}$ ratios to provide apparent ages for the water bodies sampled along the Amazon plume.

\&Nd mass balance calculation. The $\mathrm{Nd}$ isotope mass balance considers three dissolved Nd fractions: the remaining Amazon River fraction, $f_{\mathrm{Ama}}$, the fraction from the Atlantic seawater endmember, $f_{\text {Atl }}$, and the fraction released from suspended sediments, $f_{\text {sed }}$. We do not take into account coagulated $\mathrm{Nd}$ in this mass balance as it has been transferred to the particulate phase. If a subfraction of coagulated $\mathrm{Nd}$ were to desorb and regain the dissolved solution phase, it is automatically included in $f_{\text {Ama }}$. We assume that $\mathrm{Nd}$ in the $f_{\text {Atl }}$ fraction mixes conservatively in the salinity gradient, as it is predominantly bound to $<10-\mathrm{kDa}$ colloids. We assume that the three dissolved $\mathrm{Nd}$ fractions, $f_{\text {Ama }}, f_{\mathrm{Atl}}$ and $f_{\text {sed }}$, have corresponding $\varepsilon \mathrm{Nd}_{\mathrm{Ama}}, \varepsilon \mathrm{Nd}_{\mathrm{Atl}}$ and $\varepsilon \mathrm{Nd}_{\text {sed }}$ of $-8.8,-12.1$ and -10.7 , respectively. Calculated fractions that were not significantly different from 0 and 1 have been reset to 0 and 1, respectively. The mass balance was not calculated for 3 deep samples of high $\mathrm{Nd}$ concentrations and slightly lower $\varepsilon N d$ than the highest salinity sample taken as Atlantic endmember (Supplementary Discussion). As the $\varepsilon \mathrm{Nd}$ of the three endmembers span a relatively narrow range, the uncertainties on the independent variables, $f$, are relatively large. We therefore average results over three salinity ranges in the gradient $(0-10,17.5$ and $28-30$ salinity, see Supplementary Table 2). 


\section{References}

1. Jeandel, C. Concentration and isotopic composition of Nd in the South Atlantic Ocean. Earth Planet. Sci. Lett. 117, 581-591 (1993).

2. Piepgras, D. J. \& Wasserburg, G. J. Rare earth element transport in the western North Atlantic inferred from Nd isotopic observations. Geochim. Cosmochim. Acta 51, 1257-1271 (1987).

3. Molina-Kescher, M., Frank, M. \& Hathorne, E. South Pacific dissolved Nd isotope compositions and rare earth element distributions: water mass mixing versus biogeochemical cycling. Geochim. Cosmochim. Acta 127, 171-189 (2014).

4. Elderfield, H. \& Greaves, M. J. The rare earth elements in seawater. Nature 296, 214-219 (1982)

5. Rutberg, R. L., Hemming, S. R. \& Goldstein, S. L. Reduced North Atlantic Deep Water flux to the glacial Southern Ocean inferred from neodymium isotope ratios. Nature 405, 935-938 (2000).

6. Roberts, N. L., Piotrowski, A. M., McManus, J. F. \& Keigwin, L. D. Synchronous deglacial overturning and water mass source changes. Science 327, 75-78 (2010)

7. Martin, J.-M., Hogdahl, O. T. \& Philippot, J. C. Rare earth element supply to the ocean. J. Geophys. Res. 81, 3119-3124 (1976).

8. Goldstein, S. J. \& Jacobsen, S. B. Rare earth elements in river waters. Earth Planet. Sci. Lett. 89, 35-47 (1988).

9. Elderfield, H., Upstill-Goddard, R. \& Sholkovitz, E. R. The rare earth elements in rivers, estuaries, and coastal seas and their significance to the composition of ocean waters. Geochim. Cosmochim. Acta 54, 971-991 (1990).

10. Greaves, M. J., Statham, P. J. \& Elderfield, H. Rare earth element mobilization from marine atmospheric dust into seawater. Mar. Chem. 46, 255-260 (1994).

11. Henry, F., Jeandel, C., Dupré, B. \& Minster, J. F. Particulate and dissolved $\mathrm{Nd}$ in the western Mediterranean Sea: sources, fate and budget. Mar. Chem. 45, 283-305 (1994).

12. Jeandel, C., Bishop, J. K. \& Zindler, A. Exchange of neodymium and its isotopes between seawater and small and large particles in the Sargasso Sea. Geochim. Cosmochim. Acta 59, 535-547 (1995).

13. Tachikawa, K., Jeandel, C. \& Roy-Barman, M. A new approach to the Nd residence time in the ocean: the role of atmospheric inputs. Earth Planet. Sci. Lett. 170, 433-446 (1999).

14. Tachikawa, K., Athias, V. \& Jeandel, C. Neodymium budget in the modern ocean and paleo-oceanographic implications. J. Geophys. Res. 108, 3254 (2003).

15. Arsouze, T., Dutay, J. C., Lacan, F. \& Jeandel, C. Reconstructing the Nd oceanic cycle using a coupled dynamical-biogeochemical model. Biogeosciences $\mathbf{6}$, 2829-2846 (2009)

16. Rempfer, J., Stocker, T. F., Joos, F., Dutay, J.-C. \& Siddall, M. Modelling $\mathrm{Nd}$-isotopes with a coarse resolution ocean circulation model: Sensitivities to model parameters and source/sink distributions. Geochim. Cosmochim. Acta 75, 5927-5950 (2011)

17. Pearce, C. R., Jones, M. T., Oelkers, E. H., Pradoux, C. \& Jeandel, C. The effect of particulate dissolution on the neodymium $(\mathrm{Nd})$ isotope and rare earth element (REE) composition of seawater. Earth Planet. Sci. Lett. 369-370, 138-147 (2013)

18. Jones, M. T. et al. Riverine particulate material dissolution as a significant flux of strontium to the oceans. Earth Planet. Sci. Lett. 355-356, 51-59 (2012).

19. Sholkovitz, E. R. The aquatic geochemistry of rare earth element in river and estuaries. Aquat. Geochem. 1, 1-34 (1995).

20. Byrne, R. H. \& Sholkovitz, E. R. Handbook on the Physics and Chemistry of Rare Earths 23Elsevier, 1996).

21. Kim, I. \& Kim, G. Submarine groundwater discharge as a main source of rare earth elements in coastal waters. Mar. Chem. 160, 11-17 (2014)

22. Singh, S. P., Singh, S. K., Goswami, V., Bhushan, R. \& Rai, V. K. Spatial distribution of dissolved neodymium and $\varepsilon \mathrm{Nd}$ in the Bay of Bengal: Role of particulate matter and mixing of water masses. Geochim. Cosmochim. Acta 94, 38-56 (2012).

23. Johannesson, K. H. \& Tang, J. Comment on 'Effects of organic ligands on fractionation of rare earth elements (REEs) in hydroponic plants: An application to the determination of binding capacities by humic acid for modelling' by Ding et al. [Chemosphere 65 (2006) 1942-1948]. Chemosphere 68, 1392-1393 (2007)

24. Lacan, F. \& Jeandel, C. Neodymium isotopes as a new tool for quantifying exchange fluxes at the continent-ocean interface. Earth Planet. Sci. Lett. 232, 245-257 (2005)

25. Rickli, J. et al. Neodymium and hafnium boundary contributions to seawater along the West Antarctic continental margin. Earth Planet. Sci. Lett. 394, 99-110 (2014)

26. Eckert, J. M. \& Sholkovitz, E. R. The flocculation of iron, aluminium and humates from river water by electrolytes. Geochim. Cosmochim. Acta 40, 847-848 (1976).

27. Boyle, E. et al. On the chemical mass-balance in estuaries. Geochim. Cosmochim. Acta 38, 1719-1728 (1974)

28. Goldstein, S. J. \& Jacobsen, S. B. REE in the Great Whale River estuary, northwest Quebec. Earth Planet. Sci. Lett. 88, 241-252 (1988).
29. Sholkovitz, E. R. The geochemistry of rare earth elements in the Amazon River estuary. Geochim. Cosmochim. Acta 57, 2181-2190 (1993).

30. Sholkovitz, E. \& Szymczak, R. The estuarine chemistry of rare earth elements: comparison of the Amazon, Fly, Sepik and the Gulf of Papua systems. Earth Planet. Sci. Lett. 179, 299-309 (2000).

31. Goldstein, S. J. \& Jacobsen, S. B. The Nd and Sr isotopic systematics of river-water dissolved material: Implications for the sources of $\mathrm{Nd}$ and $\mathrm{Sr}$ in seawater. Chem. Geol. 66, 245-272 (1987).

32. Barroux, G. A. et al. Seasonality of dissolved element fluxes in the Amazon River endmember. Geochim. Cosmochim. Acta 70, A38-A38 (2006).

33. Sonke, J. E. \& Salters, V. J. M. Lanthanide-humic substances complexation. I. Experimental evidence for a lanthanide contraction effect. Geochim. Cosmochim. Acta 70, 1495-1506 (2006).

34. Moore, W. S., Astwood, H. \& Lindstrom, C. Radium isotopes in coastal waters on the Amazon shelf. Geochim. Cosmochim. Acta 59, 4285-4298 (1995).

35. Li, Y.-H., Mathieu, G., Biscaye, P. \& Simpson, H. J. The flux of 226Ra from estuarine and continental shelf sediments. Earth Planet. Sci. Lett. 37, 237-241 (1977).

36. Moore, W. S. Ages of continental shelf waters determined from $223 \mathrm{Ra}$ and 224Ra. J. Geophys. Res. 105, 22117-22122 (2000).

37. Moore, W. S. \& Krest, J. Distribution of 223Ra and 224Ra in the plumes of the Mississippi and Atchafalaya Rivers and the Gulf of Mexico. Mar. Chem. 86, 105-119 (2004).

38. Viers, J. et al. Seasonal and provenance controls on Nd-Sr isotopic compositions of Amazon rivers suspended sediments and implications for $\mathrm{Nd}$ and Sr fluxes exported to the Atlantic Ocean. Earth Planet. Sci. Lett. 274, 511-523 (2008)

39. Stordal, M. C. \& Wasserburg, G. J. Neodymium isotopic study of Baffin Bay water: sources of REE from very old terranes. Earth Planet. Sci. Lett. 77, 259-272 (1986)

40. Filizola, N. \& Guyot, J. L. The use of Doppler technology for suspended sediment discharge determination in the River Amazon/L'utilisation des techniques Doppler pour la détermination du transport solide de l'Amazone. Hydrolog. Sci. J. 49, 143-153 (2004).

41. Milliman, J. D. \& Farnsworth, K. L. A Global Synthesis (Cambridge University Press, 2011).

42. Milliman, J. D. \& Syvitski, J. P. M. Geomorphic Tectonic Control of sediment disccahrge to the ocean-The importance of small mountainous rivers. J. Geol. 100, 525-544 (1992).

43. Syvitski, J. P. M., Vörösmarty, C. J., Kettner, A. J. \& Green, P. Impact of humans on the flux of terrestrial sediment to the global coastal ocean. Science 308, 376-380 (2005).

44. Peucker-Ehrenbrink, B. Land2Sea database of river drainage basin sizes, annual water discharges, and suspended sediment fluxes. Geochem. Geophys. Geosyst. 10, Q06014 (2009)

45. Lugmair, G. W., Shimamura, T., Lewis, R. S. \& Anders, E. Samarium-146 in the Early Solar System: Evidence from Neodymium in the Allende Meteorite. Science 222, 1015-1018 (1983).

46. Révillon, S. et al. The provenance of sediments in the Gulf of Lions, western Mediterranean Sea. Geochem. Geophys. Geosyst. 12, Q08006 (2011).

47. DePaolo, D. J. \& Wasserburg, G. J. Nd isotopic variations and petrogenetic models. Geophys. Res. Lett. 3, 249-252 (1976).

48. Rousseau, T. C. C. et al. Rare earth element analysis in natural waters by multiple isotope dilution-sector field ICP-MS. J. Anal. Atom. Spectrom. 28, 573-584 (2013).

49. van Beek, P., Souhaut, M. \& Reyss, J. L. Measuring the radium quartet (228Ra, 226Ra, 224Ra, 223Ra) in seawater samples using gamma spectrometry. J. Environ. Radioact. 101, 521-529 (2010).

50. Moore, W. S. \& Arnold, R. Measurement of 223Ra and 224Ra in coastal waters using a delayed coincidence counter. J. Geophys. Res. 101, 1321-1329 (1996).

51. Nozaki, Y., Lerche, D., Alibo, D. S. \& Snidvongs, A. The estuarine geochemistry of rare earth elements and indium in the Chao Phraya River, Thailand. Geochim. Cosmochim. Acta 64, 3983-3994 (2000).

52. Lawrence, M. G. \& Kamber, B. S. The behaviour of the rare earth elements during estuarine mixing--revisited. Mar. Chem. 100, 147-161 (2006).

53. Hoyle, J., Elderfield, H., Gledhill, A. \& Greaves, M. The behaviour of the rare earth elements during mixing of river and sea waters. Geochim. Cosmochim. Acta 48, 143-149 (1984).

54. Åström, M. E. et al. Attenuation of rare earth elements in a boreal estuary Geochim. Cosmochim. Acta 96, 105-119 (2012).

55. Elderfield, H., Upstill-Goddard, R. \& Sholkovitz, E. The rare earth elements in rivers, estuaries, and coastal seas and their significance to the composition of ocean waters. Geochim. Cosmochim. Acta 54, 971-991 (1990).

\section{Acknowledgements}

We thank the French CNRS and Brazilian CNPq for funding the PhD scholarship of T.C.C.R., and research grant ANR-05-BLAN-0179 from the French Agence Nationale de 
Recherche. We are also thankful to the The RV Antea crew, Kathy Pradoux, Bruno Hamelin, Remy Chuchla, Fred Candaudap, Pierre Brunet, François Lacan, Melanie Grenier, Alex Costa, Jacques Grelet, Fabrice Roubault, Lionel Scouarnec, Olivier Radakovitch, Lars-Eric Heimbürger, Manu Henry, Johnatan Prunier and Kazuyo Tachikawa for their help in the field, in the lab and during discussions.

\section{Author contributions}

C.J., P.S., J.E.S. and G.B. designed and coordinated the study. T.C.C.R., J.E.S., J.C., P.v.B., M.S. and C.J. performed sampling and analysis. J.E.S. wrote the manuscript draft and all authors discussed and helped improve the final version.

\section{Additional information}

Supplementary Information accompanies this paper at http://www.nature.com/ naturecommunications
Competing financial interests: The authors declare no competing financial interests.

Reprints and permission information is available online at http://npg.nature.com/ reprintsandpermissions/

How to cite this article: Rousseau, T. C. C. et al. Rapid neodymium release to marine waters from lithogenic sediments in the Amazon estuary. Nat. Commun. 6:7592 doi: 10.1038/ncomms8592 (2015).

\section{(c) (i)}

This work is licensed under a Creative Commons Attribution 4.0 International License. The images or other third party material in this article are included in the article's Creative Commons license, unless indicated otherwise in the credit line; if the material is not included under the Creative Commons license, users will need to obtain permission from the license holder to reproduce the material. To view a copy of this license, visit http://creativecommons.org/licenses/by/4.0/ 